\title{
BMJ Open Effectiveness of a chronic obstructive pulmonary disease integrated care pathway in a regional health system: a propensity score matched cohort study
}

\author{
Christine Xia Wu, ${ }^{1}$ Chi Hong Hwang, ${ }^{1}$ Woan Shin Tan, ${ }^{2,3}$ Kai Pik Tai, ${ }^{1}$ \\ Lynette Siang Lim Kwek, ${ }^{4}$ Thong Gan Chee, ${ }^{4}$ Yee Mun Choo, ${ }^{5}$ \\ Francis Wei Loong Phng, ${ }^{1}$ Gerald Seng Wee Chua ${ }^{6}$
}

To cite: Wu CX, Hwang $\mathrm{CH}$, Tan WS, et al. Effectiveness of a chronic obstructive pulmonary disease integrated care pathway in a regional health system: a propensity score matched cohort study. BMJ Open 2018;8:e019425. doi:10.1136/ bmjopen-2017-019425

- Prepublication history for this paper is available online. To view these files, please visit the journal online (http://dx.doi. org/10.1136/bmjopen-2017019425).

Received 5 September 2017 Revised 6 February 2018 Accepted 8 February 2018
Check for updates

For numbered affiliations see end of article.

Correspondence to Christine Xia Wu; christine_wu@nuhs.edu.sg

\section{ABSTRACT}

Objective The chronic obstructive pulmonary disease (COPD) integrated care pathway (ICP) programme was designed and implemented to ensure that the care for patients with COPD is comprehensive and integrated across different care settings from primary care to acute hospital and home. We evaluated the effectiveness of the ICP programme for patients with COPD.

Design, setting and participants $A$ retrospective propensity score matched cohort study was conducted comparing differences between programme enrolees and propensity-matched non-enrolees in a Regional Health System in Singapore. Data on patients diagnosed with COPD who enrolled in the programme $(n=95)$ and patients who did not enrol $(n=6330)$ were extracted from the COPD registry and hospital administrative databases. Enrolees and non-enrolees were propensity score matched. Outcome measures The risk of COPD hospitalisations and COPD hospital bed days savings were compared between the groups using a difference-in-difference strategy and generalised estimating equation approach. Adherence with recommended care elements for the COPD-ICP group was measured quarterly at baseline and during a 2-year follow-up period.

Results Compared with non-enrolees, COPD hospitalisation risk for ICP programme enrolees was significantly lower in year 2 (incidence rate ratio (IRR): $0.73 ; 95 \% \mathrm{Cl} 0.54$ to 1.00). Similarly, COPD hospital bed days was significantly lower for enrolees in year 2 (IRR: $0.78 ; 95 \% \mathrm{Cl} 0.64$ to 0.95$)$. ICP programme patients had sustained improvements in compliance with all recommended care elements for patients with COPD. The overall all-or-none care bundle compliance rate had improved from $28 \%$ to $54 \%$.

Conclusion The study concluded that the COPD-ICP programme was associated with reductions in COPD hospitalisation risk and COPD health utilisation in a 2-year follow-up period.

\section{BACKGROUND}

Chronic obstructive pulmonary disease (COPD) is a major cause of chronic disease morbidity and mortality worldwide. The
Strengths and limitations of this study

- Examined compliance with care elements in the chronic obstructive pulmonary disease integrated care pathway (COPD-ICP) programme based on risk and severity profiles of patients over time.

- Selection bias was addressed through the use of propensity score matching.

- This provides evidence that the COPD-ICP programme is effective in reducing acute care resource use within a regional health system.

- While we tried to minimise differences at baseline between the COPD-ICP and control groups, we were only able to achieve balance for observed covariates and therefore our study only implies association and not causation.

disease is a global health problem with a worldwide prevalence of $10.1 \% .^{1}$ In Singapore, COPD is the seventh principal cause of death and the seventh most common condition for hospitalisation. ${ }^{2}$ COPD patients with complications spent a longer duration in hospitals with an average of 7.7 days, which is $79 \%$ longer than COPD patients without complications who spent an average of 4.3 days. ${ }^{3}$ In year 2011, the COPD 30-day readmission rate in Alexandra Hospital of Jurong Health Services (JurongHealth) was around $38 \%$, which was relatively higher than the national COPD 30-day readmission rate of $22 \%{ }^{4}$

The international Global Initiative for Chronic Obstructive Lung Disease (GOLD) standards for COPD recommends the use of spirometry as a benchmark for the accurate and repetitive measurement of lung function. ${ }^{5}$ However, in Singapore, most general practice clinics do not offer the spirometry services necessary for the early diagnosis and staging of COPD to enable appropriate 


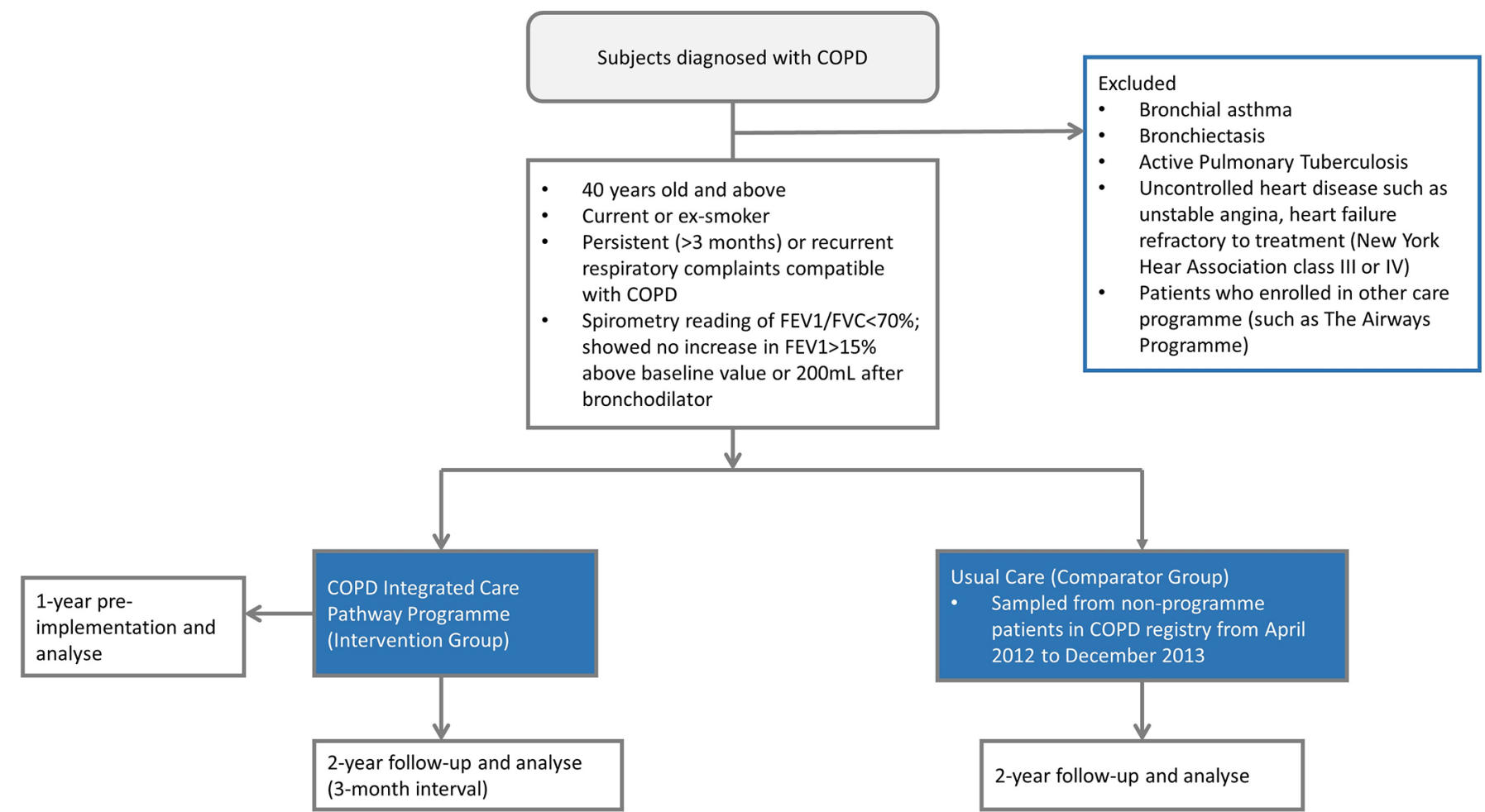

Figure 1 Identification of the study cohort. COPD, chronic obstructive pulmonary disease; FEV1, forced expiratory volume in $1 \mathrm{~s}$; FVC, forced vital capacity.

disease care. Patients with poor management of COPD have frequent relapse of COPD exacerbations, contributing to the burden of the disease in the acute setting. In order to achieve a cost-effective care model, Alexandra Hospital launched a COPD-ICP programme in April 2012 which was funded by the Ministry of Health $(\mathrm{MOH})$ in Singapore. The programme sought to coordinate care across the different healthcare settings. It also aimed to provide comprehensive care for patients with COPD at different stages of their disease which involves primary, hospital-based and palliative care. The programme envisaged the coordination of care across different sites from primary to home and hospital care. ${ }^{6}$ The objectives of the programme were to improve the overall control of the disease and the quality of life of patients with COPD, particularly those with partly controlled and uncontrolled COPD, and reduce the risk of COPD hospital admissions and healthcare utilisation.

The programme adopted a coordinated and multidisciplinary approach to the management of patients' medical conditions. Systematic review showed that most common components of integrated care programmes were self-management support and patient education, often combined with structured clinical follow-up and case management. ${ }^{7}$ Case managers worked with the multidisciplinary team of doctors, nurses, respiratory technologists, pharmacists, physiotherapists and medical social workers to develop a customised plan of care for each patient, empowering patients towards self-management through education and to coordinate referrals and patients' appointments across the different care sites.

\section{Objective}

The primary aim of this study was to assess whether patients in the COPD-ICP group had lower COPD-related hospitalisations and COPD hospital bed days than the control group. The secondary aim was to determine whether the patients in the COPD-ICP group had better adherence to the recommended care elements. ${ }^{8}$

\section{METHODS}

\section{Study design}

A retrospective propensity score matched cohort study design was applied in this study. ${ }^{8}$ This study design had been used instead of the randomised controlled trial design as the use of the latter was limited by practical and ethical concerns. First, the COPD integrated care pathway (ICP) programme had been implemented in Alexandra Hospital for almost 2 years. Due to the limitation of care resources, it would be infeasible to run two care programmes concurrently (usual care programme and COPD-ICP programme) for a randomised controlled trial as this would be more costly and time-consuming. Second, it might be unethical to deprive patients of the potentially useful COPD-ICP programme intervention compared with the usual conventional care in a randomised controlled trial. ${ }^{910}$

\section{Regional health system}

In 2012, Singapore public healthcare was provided by six regional healthcare systems (RHSs): Alexandra Health System, Eastern Health Alliance, National Healthcare 
Table 1 The chronic obstructive pulmonary disease integrated care pathway (COPD-ICP) programme key care elements

\begin{tabular}{|c|c|c|c|c|c|c|c|}
\hline \multirow[b]{2}{*}{ Key care element } & \multirow[b]{2}{*}{ At-risk } & \multirow{2}{*}{$\begin{array}{l}\text { Group A } \\
\text { Low risk, less } \\
\text { symptoms }\end{array}$} & \multirow{2}{*}{$\begin{array}{l}\text { Group B } \\
\text { Low risk, } \\
\text { more } \\
\text { symptoms }\end{array}$} & \multirow{2}{*}{$\begin{array}{l}\text { Group C } \\
\text { High } \\
\text { risk, less } \\
\text { symptoms }\end{array}$} & \multirow{2}{*}{$\begin{array}{l}\text { Group D } \\
\text { High risk, } \\
\text { more } \\
\text { symptoms }\end{array}$} & \multirow[b]{2}{*}{$\begin{array}{l}\text { In } \\
\text { exacerbation }\end{array}$} & \multirow[b]{2}{*}{$\begin{array}{l}\text { Key care } \\
\text { element } \\
\text { administered by }\end{array}$} \\
\hline & & & & & & & \\
\hline 1. Smoking prevention & $\checkmark$ & & & & & & $\begin{array}{l}\text { Doctor, case } \\
\text { manager, } \\
\text { pharmacist }\end{array}$ \\
\hline 3. Differential diagnosis & $\checkmark$ & & & & & & $\begin{array}{l}\text { Doctor, case } \\
\text { manager }\end{array}$ \\
\hline 4. Spirometric diagnosis & $\checkmark$ & $\begin{array}{l}\text { 18-24 monthly } \\
\text { clinician suspec } \\
\text { grouping has cr }\end{array}$ & $\begin{array}{l}\text { or when } \\
\text { cts patient } \\
\text { hanged }\end{array}$ & & & & $\begin{array}{l}\text { Doctor, case } \\
\text { manager, } \\
\text { spirometry } \\
\text { technologist }\end{array}$ \\
\hline 6. Drug optimisation & & $\checkmark$ & $\checkmark$ & $\checkmark$ & $\checkmark$ & $\checkmark$ & $\begin{array}{l}\text { Doctor, case } \\
\text { manager, } \\
\text { pharmacist }\end{array}$ \\
\hline $\begin{array}{l}\text { 7. Influenza vaccination } \\
\text { (yearly) }\end{array}$ & & $\begin{array}{l}\text { Only for } \\
\text { elderly } \\
\text { ( } \geq 65 \text { years) } \\
\text { and those } \\
\text { who have } \\
\text { concomitant }\end{array}$ & $\checkmark$ & $\checkmark$ & $\checkmark$ & & $\begin{array}{l}\text { Doctor, case } \\
\text { manager }\end{array}$ \\
\hline $\begin{array}{l}\text { 10. Acute non- } \\
\text { invasive ventilation }\end{array}$ & & & & & & $\checkmark$ & $\begin{array}{l}\text { Doctor, case } \\
\text { manager }\end{array}$ \\
\hline $\begin{array}{l}\text { 11. Supported } \\
\text { restructured hospital/ } \\
\text { emergency department } \\
\text { discharge }\end{array}$ & & & & & & $\checkmark$ & $\begin{array}{l}\text { Doctor, case } \\
\text { manager, ICP } \\
\text { coordinator, } \\
\text { medical social } \\
\text { worker }\end{array}$ \\
\hline 12. Home oxygen & & & & $\checkmark$ & $\checkmark$ & & $\begin{array}{l}\text { Doctor, case } \\
\text { manager }\end{array}$ \\
\hline $\begin{array}{l}\text { 13. Advance care } \\
\text { planning }\end{array}$ & & & & $\checkmark$ & $\checkmark$ & & $\begin{array}{l}\text { Doctor, case } \\
\text { manager, medical } \\
\text { social worker }\end{array}$ \\
\hline
\end{tabular}

Group (NHG), National University Health System (NUHS), JurongHealth and Singapore Health Services. Together, these RHSs provided $80 \%$ of all acute care services. ${ }^{11}$ This study used a COPD registry which was maintained by three regional health systems (JurongHealth, NHG and NUHS). ${ }^{12}$ Patients diagnosed with COPD who had at least one specialist outpatient visit record in this COPD registry from April 2012 to June
2013 were eligible to be included in the study. The standard COPD care in the RHSs was not expected to differ from the clinical practice guidelines set by the $\mathrm{MOH}$, Singapore. $^{13}$

\section{Participants}

Figure 1 shows the inclusion and exclusion criteria for patients' enrolment into the COPD programme. We 
Table 2 Baseline profile of patients with chronic obstructive pulmonary disease (COPD) enrolled in integrated care pathway and control groups

\begin{tabular}{|c|c|c|c|c|c|c|}
\hline \multirow[b]{3}{*}{ Variable } & Unmatched & Unmatched & Matched & Matched & Unmatched & Matched \\
\hline & Enrolees & Non-enrolees & Enrolees & Non-enrolees & \multirow{2}{*}{$\begin{array}{l}\text { Standardised } \\
\text { difference }\end{array}$} & \multirow{2}{*}{$\begin{array}{l}\text { Standardised } \\
\text { difference }\end{array}$} \\
\hline & $\mathrm{n}=95$ & $n=6330$ & $\mathrm{n}=92$ & $\mathrm{n}=92$ & & \\
\hline \multicolumn{7}{|l|}{ Demographics } \\
\hline Age, mean (SD) & $72.7(8.8)$ & $72.3(11.1)$ & $72.7(8.9)$ & 72.2 (11.1) & 0 & -0.1 \\
\hline Male, n (\%) & $92(0.97)$ & $4960(0.78)$ & $89(0.97)$ & $88(0.96)$ & -0.6 & -0.1 \\
\hline Rental flat (yes), n (\%) & $18(0.19)$ & $730(0.12)$ & $16(0.17)$ & $15(0.16)$ & -0.2 & 0 \\
\hline \multicolumn{7}{|l|}{ Race } \\
\hline Chinese, n (\%) & $60(0.63)$ & $4951(0.78)$ & $60(0.65)$ & $55(0.60)$ & 0.3 & -0.1 \\
\hline Malay, n (\%) & $20(0.21)$ & $609(0.10)$ & $17(0.18)$ & $23(0.25)$ & -0.3 & 0.2 \\
\hline Indian, n (\%) & $12(0.13)$ & $497(0.08)$ & $12(0.13)$ & $12(0.13)$ & -0.2 & 0 \\
\hline \multicolumn{7}{|l|}{ Comorbid and severity } \\
\hline $\begin{array}{l}\text { Charlson Comorbidity } \\
\text { Index, mean (SD) }\end{array}$ & $1.54(1.18)$ & $1.9(2.02)$ & $1.55(1.20)$ & $1.59(1.28)$ & 0.2 & 0 \\
\hline \multicolumn{7}{|l|}{ Previous 1-year utilisation } \\
\hline $\begin{array}{l}\text { Tiotropium dispensed } \\
\text { previous } 1 \text { year, } \mathrm{n}(\%)\end{array}$ & $41(0.43)$ & $573(0.09)$ & $38(0.41)$ & $39(0.42)$ & -0.8 & 0 \\
\hline $\begin{array}{l}\text { COPD admission count } \\
\text { previous } 1 \text { year, mean } \\
\text { (SD) }\end{array}$ & $0.78(1.15)$ & $0.2(0.68)$ & $0.68(1.03)$ & $0.54(1.16)$ & -0.6 & -0.1 \\
\hline $\begin{array}{l}\text { COPD hospital days } \\
\text { previous } 1 \text { year, mean } \\
\text { (SD) }\end{array}$ & $2.96(8.02)$ & $0.85(3.87)$ & $2.46(7.52)$ & $1.91(5.23)$ & -0.3 & -0.1 \\
\hline
\end{tabular}

Continuous variables are reported as mean (SD), while dichotomous variables are reported as number with condition (percentage).

classified each patient enrolled into the programme into four groups A, B, C and D based on the Patient Group Classification from the updated GOLD guidelines. ${ }^{14}$ Patients with COPD were identified based on the International Classification of Diseases Tenth Revision diagnostic codes (J40.xx and J47.xx). ${ }^{3}$ Patients in the COPD-ICP group were sampled from the programme patients in the COPD registry who received care from Alexandra Hospital (of JurongHealth RHS) from April 2012 to June 2013. A control group was formed from non-enrolees using the matching method. Non-enrolees referred to non-programme patients with Specialist Outpatient Clinic (SOC) record $(\mathrm{s})$ in the COPD registry and did not receive care from Alexandra Hospital from April 2012 to June 2013. All data were collected over a 1-year pre-enrolment and a 2-year follow-up (3-month interval) for the COPD-ICP group and over a 2-year period for the control group. The outcomes were compared between the COPD-ICP and control groups.

\section{The COPD-ICP programme}

Standard care for patients with COPD can be fragmented and uncoordinated due to poor tracking and monitoring of the care plans for the patients. There are also challenges faced in streamlining and coordinating care between the secondary and primary levels due to the lack of a common information system. ${ }^{15}$ Thus, the COPD-ICP programme has been designed to better integrate and coordinate the spectrum of services for patients diagnosed with COPD, beyond the acute hospital setting. Table 1 shows the recommended key elements for each group of patients. The recommended key care elements were determined by the MOH steering committee meeting in 2010 and all care elements were implemented since April 2012. ${ }^{16}$ A collaborative team consisting of doctors, nurses, respiratory technologists, pharmacists, physiotherapists and medical social workers is responsible for administering the respective key care elements in table 1 .

Patients suspected of having COPD would undergo a spirometry test. On diagnosis of COPD and with their verbal consent, patients would be enrolled into the COPD-ICP programme. Patients enrolled into the programme would be classified based on the Patient Group Classification from the updated GOLD guidelines. ${ }^{14}$ Thereafter, the patients' condition would be assessed on every SOC or polyclinic visit and would then be reclassified accordingly if there was a change in the severity of their condition.

On enrolment into the programme, case managers would initiate key care elements 1-9. For groups $\mathrm{C}$ and D, key care elements 10-13 would be assessed and administered by case managers whenever necessary throughout the follow-up period. Case managers would readminister 
Table 3 Unadjusted and adjusted ratios in chronic obstructive pulmonary disease (COPD)-related hospital admissions and hospital days

Average number of COPD-related hospital Adjusted COPD-related hospital admissions per patient (unadjusted) admissions* $^{*}$

\begin{tabular}{|c|c|c|c|c|c|}
\hline & Enrolees & Non-enrolees & Ratio & $\begin{array}{l}\text { Incidence rate } \\
\text { ratio }\end{array}$ & $95 \% \mathrm{Cl}$ \\
\hline \multicolumn{6}{|c|}{ Total sample excluding those who died $\dagger$} \\
\hline First year follow-up & 0.73 & 0.78 & 0.94 & 0.82 & 0.60 to 1.12 \\
\hline Second year follow-up & 0.75 & 0.89 & 0.84 & $0.73 \ddagger$ & 0.54 to 1.00 \\
\hline \multicolumn{6}{|l|}{ Alive at start of each yeart } \\
\hline First year follow-up & 0.83 & 0.83 & 1.00 & 0.79 & 0.57 to 1.09 \\
\hline Second year follow-up & 0.82 & 0.88 & 0.93 & $0.72 \ddagger$ & 0.52 to 0.99 \\
\hline
\end{tabular}

Average number of COPD-related hospital days per patient (unadjusted)

Adjusted COPD-related hospital days*

\begin{tabular}{|c|c|c|c|c|c|}
\hline & Enrolees & Non-enrolees & Ratio & $\begin{array}{l}\text { Incidence rate } \\
\text { ratio }\end{array}$ & $95 \% \mathrm{Cl}$ \\
\hline \multicolumn{6}{|c|}{ Total sample excluding those who died $\dagger$} \\
\hline First year follow-up & 2.75 & 2.49 & 1.10 & 0.88 & 0.71 to 1.08 \\
\hline Second year follow-up & 3.16 & 3.22 & 0.98 & $0.78 \ddagger$ & 0.64 to 0.95 \\
\hline \multicolumn{6}{|l|}{ Alive at start of each year† } \\
\hline First year follow-up & 3.99 & 2.63 & 1.52 & 1.17 & 0.95 to 1.44 \\
\hline Second year follow-up & 3.67 & 3.19 & 1.15 & $0.83 \S$ & 0.67 to 1.02 \\
\hline
\end{tabular}

*Adjusted for age, sex, ethnic group, rental flat, coronary heart disease, chronic kidney disease, hypertension, dyslipidaemia, obesity, asthma, diabetes mellitus, usage of tiotropium; generalised estimating equation with the log link function, Poisson distribution and exchangeable covariance structure; incidence rate ratio $<1$ indicates smaller odds of hospitalisation.

†Total sample $n=184, n_{1}=172$ alive at start of year $1, n_{2}=162$ alive at start of year 2 .

$\ddagger \mathrm{P}<0.05$.

$\S \mathrm{P}<0.10$.

the care elements every 3-4 months, when patients returned for their appointments. All care elements were traced by the Patient Care Management system. They would also call the patient 48 hours post discharge to reinforce patient education and drugs optimisation, where they play a pivotal role in linking patients to community resources and early detection and management. Pulmonary rehabilitation was not an element of the COPD-ICP programme, but the case manager would refer ambulant patients for pulmonary rehabilitation in hospitals where a suitable rehabilitation programme would be tailored for the patient, which includes elements such as physical training, disease education and nutritional, psychological and behavioural intervention. ${ }^{17}$

\section{Data source/measurement}

The three main sources of data were (1) COPD registry which contained patient demographics, clinical information and outcome variables for patients in the COPD-ICP group as well as the control group; (2) Patient Care Management system database where case managers captured and entered data on all the recommended care elements and (3) Health System administrative databases for information on healthcare utilisation.

\section{Study variables}

Study variables included patient demographics and socioeconomic indicators (age, race, gender, nationality and housing type such as public rental housing), disease duration, programme enrolment date, eight key care elements (smoking cessation, patient education, drug optimisation, influenza vaccination, body mass index (BMI) assessment, COPD assessment test (CAT) score measurement, home oxygen therapy and advance care planning (ACP) $),{ }^{16}$ smoking history, comorbidities, disease severity, previous 1-year utilisation and clinical outcomes. The primary outcomes that were monitored in this study were COPD hospitalisation and COPD hospital bed days. COPD hospitalisation refers to COPD-related inpatient episodes at acute care hospitals managed by the three regional health clusters (JurongHealth, NHG and NUHS) within 2 years of follow-up. COPD hospital bed days refer to the calculated COPD-related inpatient bed days at acute care hospitals managed by the three regional health clusters (JurongHealth, NHG and NUHS) within 2 years of follow-up.

\section{Study size}

We had set $30 \%$ as our target for the difference in the proportion of patients admitted to the hospital between 
Table 4 All-or-none care bundle compliance for chronic obstructive pulmonary disease integrated care pathway patients in 2-year follow-up

\begin{tabular}{|c|c|c|c|c|c|c|c|c|c|c|c|c|}
\hline & \multicolumn{4}{|c|}{ 1-Year baseline (\%) } & \multicolumn{8}{|c|}{ 2-Year follow-up (\%) } \\
\hline & $\begin{array}{l}\text { FY12 } \\
\text { Q2 }\end{array}$ & $\begin{array}{l}\text { FY12 } \\
\text { Q3 }\end{array}$ & $\begin{array}{l}\text { FY12 } \\
\text { Q4 }\end{array}$ & $\begin{array}{l}\text { FY13 } \\
\text { Q1 }\end{array}$ & $\begin{array}{l}\text { FY13 } \\
\text { Q2 }\end{array}$ & $\begin{array}{l}\text { FY13 } \\
\text { Q3 }\end{array}$ & $\begin{array}{l}\text { FY13 } \\
\text { Q4 }\end{array}$ & $\begin{array}{l}\text { FY14 } \\
\text { Q1 }\end{array}$ & $\begin{array}{l}\text { FY14 } \\
\text { Q2 }\end{array}$ & $\begin{array}{l}\text { FY14 } \\
\text { Q3 }\end{array}$ & $\begin{array}{l}\text { FY14 } \\
\text { Q4 }\end{array}$ & $\begin{array}{l}\text { FY15 } \\
\text { Q1 }\end{array}$ \\
\hline Group B & 71 & 70 & 73 & 65 & 72 & 79 & 76 & 75 & 89 & 80 & 76 & 77 \\
\hline Group C & 0 & 0 & 7 & 4 & 7 & 10 & 28 & 19 & 20 & 21 & 16 & 15 \\
\hline
\end{tabular}

Patient classification is based on symptoms and risk of exacerbation, from updated the Global Initiative for Chronic Obstructive Lung Disease guidelines. $^{14}$

FY, fiscal year; group A, low risk, less symptoms; group B, low risk, more symptoms; group C, high risk, less symptoms; group D, high risk, more symptoms; $Q$, quarter.

programme enrolees and non-enrolees. Thus, a sample size of 56 patients each for the COPD-ICP group and control group was needed to have $90 \%$ power to find a statistically significant difference at the $5 \%$ significance level. ${ }^{18}$ Hence, a minimum of 62 enrolees (to account for $10 \%$ missing data) were needed to be sampled from among those who were enrolled into the programme during the study period. The matched group was drawn from the control group from the COPD registry using 1-to-1 matching. All baseline covariates collected at the baseline were used for 1-to-1 propensity score matching. ${ }^{19}$

\section{Statistical methods}

Key recommended processes of care in the COPD-ICP programme were monitored quarterly to track the adherence and progress of the programme. Patient baseline characteristics from enrolees and non-enrolees were described with mean and SD for continuous variables and number and percentage for categorical variables. Differences between COPD enrolees and non-enrolees were compared using $\chi^{2}$ statistics for categorical variables and Wilcoxon rank-sum tests for continuous variables. ${ }^{20}$

Since patients were enrolled into the programme based on the institution where they received consultation, it was likely that there would be imbalance in the baseline characteristics between enrolees and non-enrolees. Hence, we used propensity score matching to balance the baseline characteristics between enrolees and non-enrolees. ${ }^{21}$ We used multivariate logistic regression to estimate each patient's propensity score, which is the conditional probability of them being enrolled into the programme given their baseline characteristics. ${ }^{22}$ We used public rental housing as a surrogate marker for the socioeconomic covariate. Under the Public Rental Scheme, the heavily subsidised public rental housing in Singapore caters to lower income households with no other housing options. ${ }^{23}$ This indicator has been validated as a sensitive indicator of area-level socioeconomic status in Singapore. ${ }^{24}$ The covariates included in the regression were age, gender, race, comorbid conditions and previous 1-year utilisation. Smoking status and disease duration were excluded in the analysis because these two variables had $>5 \%$ missing records. We then formed pairs of enrolee and non-enrolee by using the calliper matching method, within a range of 0.2 of the SD of propensity score. ${ }^{25}$

The degree of matching on the propensity score that balanced measured covariates between treated and untreated patients was assessed using two methods. First, the mean or prevalence of each covariate was compared between treated and untreated patients. Second, standardised differences between treated and untreated patients were computed for each covariate. In this study, a standardised difference of $\leq 0.1$ had been suggested to denote negligible imbalance between the enrolees and non-enrolees to select an optimal propensity score matching model. ${ }^{26}$

We used a difference-in-difference approach to assess the effect of the programme on the outcome. This method accounts for secular trends in outcomes by subtracting the changes in outcomes in the control group from the concurrent change in the COPD-ICP group to derive the programme impact. The following equation was employed in the model:

$$
\begin{aligned}
y_{s t}= & \beta_{0}+\beta_{1} \text { COPD }-\mathrm{ICP}+\beta_{2} \text { Post } 1+\beta_{3} \text { Post } 2+ \\
& \beta_{4}(\mathrm{COPD}-\mathrm{ICP} \times \text { Post } 1)+\beta_{5}(\mathrm{COPD}-\mathrm{ICP} \times \text { Post } 2)+ \\
& \beta_{6} \text { Adjustors }+\beta_{\text {st }}
\end{aligned}
$$

where $y_{s t}$ is the dependent variable. COPD-ICP is a dummy variable which represents enrolment in the programme (COPD-ICP $=1$ ). The two time dummies (Post1 and Post2) denote the 2 years of follow-up period. The coefficient of COPD-ICP represents the difference in the outcome of interest between enrolees and non-enrolees before the ICP programme was implemented. The coefficients of the two interaction terms, COPD-ICP $\times$ Post1, COPD-ICP $\times$ Post2, reflect the impact of the ICP programme on the enrolees post implementation. 
To address the correlation between repeated annual observations in outcome across time for the same patients, we used a generalised estimating equation approach. ${ }^{27-29}$ We specified a Poisson distribution with log link for the count variables of COPD hospitalisation and COPD hospital bed days. In these regression models, the correlation matrix was assumed to be unstructured.

All analyses were conducted using Stata V.14.0.

\section{RESULTS}

We identified 95 enrolees and 6330 non-enrolees before propensity score matching. The matched sample comprised 92 enrolees and 92 non-enrolees. Baseline characteristics of the unmatched and propensity score matched samples are shown in table 2 . Before propensity score matching, about 9 out of $10(90 \%)$ of the characteristics were unbalanced. After propensity score matching, the matched patients were well matched in about 9 out of 10 covariates.

\section{Utilisation outcomes}

Table 3 presents the unadjusted and adjusted incidence rate ratio between the ICP group and the control group for COPD hospital admissions and hospital days. Considering only individuals who survived during the 2-year study time frame, the unadjusted figures showed that there were fewer COPD admissions for the ICP group than the control group in the second year follow-up. There were fewer COPD hospital days for the ICP group than the control group in the 2-year follow-up. The adjusted figures revealed that there were lower COPD admissions for the ICP group than the control group in both years of postenrolment period, with significant improvements in the second year. Similarly, there were lower COPD hospital days for the ICP group than the control group in the 2years of follow-up, with significant improvements in the second year as well. Similar results were observed for individuals who were alive at the start of each follow-up year.

\section{Process indicators}

We used an all-or-none care bundle to monitor adherence with the recommended key care elements for group A, B, C and D patients at baseline and follow-up period. The all-or-none care bundle is a process indicator which measures the percentage of patients who adhere with all of the recommended key care elements according to each patient group. ${ }^{30}$ ICP programme patients had sustained improvements in compliance with all recommended care elements for patients with COPD, namely smoking cessation, patient education, drug optimisation, influenza vaccination, BMI assessment, CAT score measurement, home oxygen therapy and ACP. ${ }^{16}$ From these results, the team was able to find the particular care elements that might have resulted in the non- $100 \%$ care bundle compliance and identify possible workflow process issues that could be improved. Table 4 shows the all-or-none care bundle performance of the process elements on a quarterly basis for the COPD-ICP programme patients across the four different groups (A, B, C and D). The programme patients who achieved the measures in the all-or-none bundle had gradually improved for all four groups from fiscal year (FY) 12 quarter (Q)2, the beginning quarter of the baseline period, to FY15 Q2, the ending quarter of the 2-year follow-up period. For group $\mathrm{A}$ and $\mathrm{B}$ patients, the all-or-none care bundle compliance rate had improved from $67 \%$ to $77 \%$ and $71 \%$ to $77 \%$, respectively. The compliance rate for group $\mathrm{C}$ and D patients had also improved from $0 \%$ to $15 \%$ and $0 \%$ to $37 \%$, respectively. The overall all-or-none care bundle compliance rate improved from $28 \%$ to $54 \%$.

\section{DISCUSSION}

The integrated care management was thought to reduce the risk of hospitalisation and hospital bed days for patients with COPD. Globally, a multidisciplinary care team comprising the clinician, case manager, coordinator and other relevant allied health members had shown to improve clinical outcomes and life expectancy of patients with COPD. ${ }^{31}$

Our study included a cohort of patients with COPD using a unique COPD disease registry. Compared with matched-control patients, programme enrolees were more compliant with processes of COPD care elements and had lower COPD hospitalisation in the 2-year follow-up. COPD hospital bed days were similarly reduced for the programme enrolees compared with the non-enrolees.

The effectiveness of the ICP programme could be attributed to several factors. The intervention from the ICP programme could have resulted in the enhanced self-management of the condition by the patient and a higher accessibility to healthcare professionals. ${ }^{32}$ As a result, these interventional effects might have prompted better management of exacerbations, hence lowering the risk of admissions. In fact, a report had shown that patient recognition of exacerbation symptoms and prompt treatment in patients with COPD improved exacerbation recovery and reduces the risk of hospitalisation. ${ }^{33}$ It is also associated with a better health-related quality of life for patients with COPD. From an international perspective, systematic review of similar integrated care models around the world had also shown positive results. ${ }^{345}$

The choice of the matched group patients using propensity scores replicated the balance in baseline characteristics between compared cohorts achieved through randomisation. This had in turn reduced the effect of selection bias due to the lack of randomisation. ${ }^{22}$ This step was vital for making valid conclusions from the economic effectiveness analysis.

Overall, we found that patients with COPD enrolled in the ICP programme experienced lower hospitalisation and COPD hospital bed days in the first two years of implementation compared with the non-enrolees. However, the study may have limited impact on patients with good compliance in the 2-year follow-up. The findings of 
other systematic reviews had shown that positive effects of ICP programmes tend to diminish with longer lengths of follow-up. ${ }^{10}$ Future evaluations could incorporate a longer-term tracking of the health outcomes of this group. Greater focus could be placed on strengthening the self-management capabilities of these patients to prevent the development of complications and disease deterioration in the longer term. Our future implementation plans include strengthening capabilities in primary and community-based care for the early detection, treatment and management of patients with COPD. ${ }^{36} 37$

We found that the ICP effects varied across patient subgroups for their care compliance. Groups A and B achieved higher care compliance than groups $\mathrm{C}$ and $\mathrm{D}$, probably due to easier administration of care at primary care clinics and lesser number of key care elements for compliance. The study has shown great potential to improve patient care by minimising care gaps and having consistent feedback from the measurements. There is also a current challenge in achieving full care bundle delivery for groups $\mathrm{C}$ and $\mathrm{D}$ patients because of the barriers of carrying out ACP. The programme may be fine-tuned with process improvements which may include care plan drafting and discharge planning, and the inclusion of technological aids such as smart phone applications to enable remote monitoring and facilitate self-management, in order to be more efficient and effective in its care delivery. There are also efforts within the ACP team to increase public awareness on the subject of ACP and how it would benefit patients in the long run.

\section{Limitations}

This research had limitations in some areas. First, as the programme was implemented in RHSs, we were unable to conduct a randomised trial. As such, patients who participated in the ICP programme might differ from non-enrolees systematically due to non-randomisation. To overcome this limitation, we had tried to adjust for selection bias using propensity score matching. However, we could not rule out the possibility of our results being influenced by unmeasured differences between case and control. $^{8}$

Second, the standard COPD care from different institutions was not expected to differ from the clinical practice guidelines set by MOH, Singapore. The effects observed could be attributed to the COPD-ICP programme. However, there could be potential bias resulting from differences between these institutions. To account for these differences, we had tried to adjust for bias using propensity score matching. However, we could not exclude the possibility that we may not be able to identify all potential variables that would contribute to bias.

Lastly, due to the non-captive healthcare system, patients were able to choose providers on an episodic basis. To minimise the impact of this potential bias on our results, we had included only patients who were consistent users of these RHSs by using the inclusion criteria of at least one specialist outpatient visit at one of the acute hospitals within the RHSs. Furthermore, we were only able to measure use and costs incurred in the RHSs. However, we do not expect consultations and admissions outside of these RHSs to differ systematically between the programme and control groups.

\section{CONCLUSION}

The study concluded that the COPD-ICP intervention was associated with reductions in COPD hospitalisation risk in a 2-year follow-up period. The COPD-ICP programme had equipped primary care partners with the relevant and adequate knowledge and skills for managing stable patients with COPD. This had helped to achieve positive clinical outcomes. The lessons learnt from this study were highlighted to the programme team and are useful for improving the design of similar programmes nationally. The COPD-ICP team had also received the programme funding extension from the MOH since April 2017 after undergoing a 5-year pilot study from April 2012 to March 2017.

\section{Author affiliations}

${ }^{1}$ Quality, Innovation and Improvement, Ng Teng Fong General Hospital and Jurong Community Hospital, Members of the NUHS, Singapore

${ }^{2}$ Health Services and Outcomes Research, National Healthcare Group, Singapore ${ }^{3}$ NTU Institute for Health Technologies, Interdisciplinary Graduate School, Nanyang Technological University, Singapore

${ }^{4}$ Clinical Operations, Ng Teng Fong General Hospital and Jurong Community Hospital, Members of the NUHS, Singapore

${ }^{5}$ Nursing Clinical Services, Ng Teng Fong General Hospital and Jurong Community Hospital, Members of the NUHS, Singapore

${ }^{6}$ Medicine Division, Ng Teng Fong General Hospital and Jurong Community Hospital, Members of the NUHS, Singapore

Acknowledgements The authors acknowledge Dr Matthias Toh, Miss Lin Jen Lee and Ms Yin Min Thaung (Information Management, NHG) for their advice and assistance in the study. The authors also wish to acknowledge Mr Zhaogi Chen for his support in data analysis and manuscript review. They also thank the two reviewers for their comments.

Contributors CXW contributed to the study concept and design, statistical analysis, interpretation of data and drafting of the manuscript. $\mathrm{CHH}$ contributed to the critical review of the study design, statistical analysis and manuscript revision. WST contributed to the statistical methods and the critical revision of the manuscript for important intellectual content. KPT performed the statistical analysis and the drafting of the manuscript. LSLK and YMC contributed to data collection and the revision of the manuscript. TGC contributed to the study design and revision of the manuscript as the operational lead of the programme. FWLP participated in the statistical analysis and the critical revision of the manuscript. GSWC participated in the conception and design of the COPD-ICP programme as the programme lead. All the authors reviewed and approved the final manuscript.

Funding This work was supported by Ministry of Health (MOH), Singapore Health Services Development Programme (HSDP) grant number MH 36: 18/95.

Competing interests None declared.

Patient consent Obtained.

Ethics approval NHG Domain Specific Review Board (DSRB Ref: 2013/01200).

Provenance and peer review Not commissioned; externally peer reviewed.

Data sharing statement An access right to the data was given to the study team in JurongHealth, the project manager and the clinician lead of the COPD-ICP programme. No additional data are available.

Open Access This is an Open Access article distributed in accordance with the Creative Commons Attribution Non Commercial (CC BY-NC 4.0) license, which permits others to distribute, remix, adapt, build upon this work non-commercially, 
and license their derivative works on different terms, provided the original work is properly cited and the use is non-commercial. See: http://creativecommons.org/ licenses/by-nc/4.0/

(C) Article author(s) (or their employer(s) unless otherwise stated in the text of the article) 2018. All rights reserved. No commercial use is permitted unless otherwise expressly granted.

\section{REFERENCES}

1. Buist AS, McBurnie MA, Vollmer WM, et al. International variation in the prevalence of COPD (the BOLD Study): a population-based prevalence study. Lancet 2007;370:741-50.

2. Ministry of Health, Singapore. Health facts 2011. Singapore: Ministry of Health, 2011.

3. Teo WS, Tan WS, Chong WF, et al. Economic burden of chronic obstructive pulmonary disease. Respirology 2012;17:120-6.

4. Lim E, Matthew N, Mok W, et al. Using hospital readmission rates to track the quality of care in public hospitals in Singapore. BMC Health Serv Res 2011;11(Suppl 1):A16.

5. Soriano JB, Zielinski J, Price D. Screening for and early detection of chronic obstructive pulmonary disease. Lancet 2009;374:721-32.

6. Kruis AL, Smidt N, Assendelft WJJ, et al. Integrated disease management interventions for patients with chronic obstructive pulmonary disease. Cochrane Database Syst Rev 2013;10:CD009437.

7. Ouwens M, Wollersheim H, Hermens R, et al. Integrated care programmes for chronically ill patients: a review of systematic reviews. Int J Qual Health Care 2005;17:141-6.

8. Wu CX, Tan WS, See RC, et al. A matched-group study protocol to evaluate the implementation of an Integrated Care Pathway programme for chronic obstructive pulmonary disease in Singapore. BMJ Open 2015;5:e005655.

9. Tan WS, Ding YY, Xia WC, et al. Effects of a population-based diabetes management program in Singapore. Am J Manag Care 2014;20:e388-e398.

10. Akl EA, Briel M, You JJ, et al. Potential impact on estimated treatment effects of information lost to follow-up in randomised controlled trials (LOST-IT): systematic review. BMJ 2012;344:e2809.

11. Lee CE, Satku K. Singapores Health Care System': What 50 Years Have Achieved. Singapore: World Scientific:47. ISBN 978-981-469607-4.

12. Toh MP, Leong HS, Lim BK. Development of a diabetes registry to improve quality of care in the National Healthcare Group in Singapore. Ann Acad Med Singapore 2009;38:546-6.

13. Ministry of Health. Chronic Obstructive Pulmonary Disease. $\mathrm{MOH}$ Clinical Practice Guidelines. Singapore: Ministry of Health, 2006.

14. Global Initiative for Chronic Obstructive Lung Disease (GOLD). Global strategy for diagnosis, management, and prevention of chronic obstructive pulmonary disease. Bethesda: Global Initiative for Chronic Obstructive Lung Disease, 2005.

15. JurongHealth. Media release: JurongHealth launches Singapore's first Integrated Care Pathway with pilot Chronic Obstructive Pulmonary Disease (COPD) Programme integrating the spectrum of services for patients across multiple sites. Singapore: Jurong Health, 2012.
16. JurongHealth. Chronic Obstructive Pulmonary Disease (COPD) Programme: Guidelines for Healthcare Professionals. Singapore: JurongHealth, 2012.

17. JurongHealth. Chronic Obstructive Pulmonary Disease (COPD) Programme Patient Handbook. Singapore: JurongHealth.

18. Whitley E, Ball J. Statistics review 4: sample size calculations. Crit Care 2002:6:335-41.

19. Austin PC. Balance diagnostics for comparing the distribution of baseline covariates between treatment groups in propensity-score matched samples. Stat Med 2009;28:3083-107.

20. du Prel JB, Röhrig B, Hommel G, et al. Choosing statistical tests: part 12 of a series on evaluation of scientific publications. Dtsch Arztebl Int 2010;107:343-8.

21. Roberts $\mathrm{MH}$, Dalal AA. Clinical and economic outcomes in an observational study of COPD maintenance therapies: multivariable regression versus propensity score matching. Int J Chron Obstruct Pulmon Dis 2012;7:221-33.

22. Austin PC. An Introduction to Propensity Score Methods for Reducing the Effects of Confounding in Observational Studies. Multivariate Behav Res 2011;46:399-424.

23. Housing \& Development Board, Singapore. Public Rental Scheme. http://www.hdb.gov.sg/cs/infoweb/residential/renting-a-flat/rentingfrom-hdb/public-rental-scheme

24. Low LL, Tay WY, Ng MJM, et al. Frequent hospital admissions in Singapore: clinical risk factors and impact of socioeconomic status. Singapore Med J 2018;59:39-43.

25. Cochran WG, Rubin DB. Controlling bias in observational studies: a review. The Indian Journal of Statistics, Series A 1973;35:417-46.

26. Austin PC, Mamdani MM. A comparison of propensity score methods: a case-study estimating the effectiveness of post-AMI statin use. Stat Med 2006;25:2084-106.

27. Garrido MM, Kelley AS, Paris J, et al. Methods for constructing and assessing propensity scores. Health Serv Res 2014;49:1701-20.

28. Nelder JA, Wedderburn RWM. Generalized Linear Models. J R Stat Soc Ser A 1972;135:370-84.

29. LIANG K-YEE, Zeger SL. Longitudinal data analysis using generalized linear models. Biometrika 1986;73:13-22.

30. Nolan T, Berwick DM. All-or-none measurement raises the bar on performance. JAMA 2006;295:1168-70.

31. Eeden SF, Burns J. A multidisciplinary approach to the treatment and management of chronic obstructive pulmonary disease. BCMJ 2008;50:143-7.

32. Casas A, Troosters T, Garcia-Aymerich J, et al. Integrated care prevents hospitalisations for exacerbations in COPD patients. Eur Respir J 2006;28:123-30.

33. Wilkinson TM, Donaldson GC, Hurst JR, et al. Early therapy improves outcomes of exacerbations of chronic obstructive pulmonary disease. Am J Respir Crit Care Med 2004;169:1298-303.

34. Thistlethwaite P. Integrating health and social care in Torbay. Improving care for Mrs Smith. London: The King's Fund, 2011.

35. Allen D, Gillen E, Rixson L. The Effectiveness of Integrated Care Pathways for Adults and Children in Health Care Settings: A Systematic Review. JBI Libr Syst Rev 2009;7:80-129.

36. Bellamy D, Smith J. Role of primary care in early diagnosis and effective management of COPD. Int J Clin Pract 2007;61:1380-9.

37. Chetty M, MacKenzie M, Douglas G, et al. Immediate and early discharge for patients with exacerbations of chronic obstructive pulmonary disease: is there a role in "real life"? Int J Chron Obstruct Pulmon Dis 2006;1:401-7. 